\title{
In sacco measurements of filter-paper degradation : rumen vs caecum
}

\author{
V Julliand ${ }^{1, G}$ Laillet ${ }^{2}$, with technical assistance of M Penning ${ }^{1}$ \\ 1INRAIENESAD, Unité associée de recherches zootechniques, BP 1607, 21036 Dijon Cedex ; $2 E N E S A D$, \\ Laboratoire de physiologie et biochimie végétale, BP 1607, 21036 Dijon Cedex, France
}

Fiber digestion is less efficient in monogastric than in polygastric herbivores (Dulphy et al, 1994, Ann Zootech, 43, 11-32). To compare the cellulolytic activity in the rumen and the equine caecum we measured the in sacco degradation of filter-paper (FP). The Nylon bag technique has never been used previously with FP.

\section{(1) Preliminary study :}

We first tested the feasibility of the method in 3 ponies and 3 donkeys (caecally-fistulated) and in 3 dry cows fitted with a rumen cannula which were fed a maintenance diet $(30 \%$ concentrate (16\% CP)-70\% lucerne-cocksfoot-hay (15\% $\mathrm{CP})$ ) in 2 meals/day. After 2 weeks adaptation, 3 bags were placed into the caecum or rumen for $48 \mathrm{~h}$. The bags were made out of Blutex T120 measured $3.5 \times 11 \mathrm{~cm}$ with pores of 48 $\mu \mathrm{m}$. Each contained $0.5 \mathrm{~g}$ FP cut into narrow strips. After $48 \mathrm{~h}$ incubation the bags were washed in a washing machine in water at $10^{\circ} \mathrm{C}$ then dried at $80^{\circ} \mathrm{C}$ for $48 \mathrm{~h}$. The residual dry matter (rDM) was calculated.

The degradation of FP was higher in cows than in ponies or donkeys after $48 \mathrm{~h}$. Ponies and donkeys had the same ability to degrade FP.
(2) Kinetic study :

We measured the kinetics of FP degradation using the same protocol described above in 4 ponies, 3 donkeys and 4 cows but withdrawing the bags after $4,8,16,24,36$ or $48 \mathrm{~h}$ from the caecum or rumen.

The analysis of variance (repeated measures) showed an interaction between time and species $(P<0.01)$. The degradation of $F P$ in the rumen of cows was more effective than in the caecum of the equids after $36 \mathrm{~h}$ and $48 \mathrm{~h}$ of incubation.

The kinetics of the rDM demonstrated that donkeys degraded cellulose quicker and to a greater extent than ponies or cows during the first $24 \mathrm{~h}$. Linear regressions confirmed that the degradation rate of FP was higher in donkeys in the first $24 \mathrm{~h}(2.76 \% / \mathrm{h})$ than in cows (2.23) or ponies(2.19).

These results confirmed that the cellulose degradation in polygastric animals is more efficient than in monogastric herbivores when the retention time is longer than $24 \mathrm{~h}$ and that donkeys are particularly effective in degrading large amounts of cellulose in a short time.

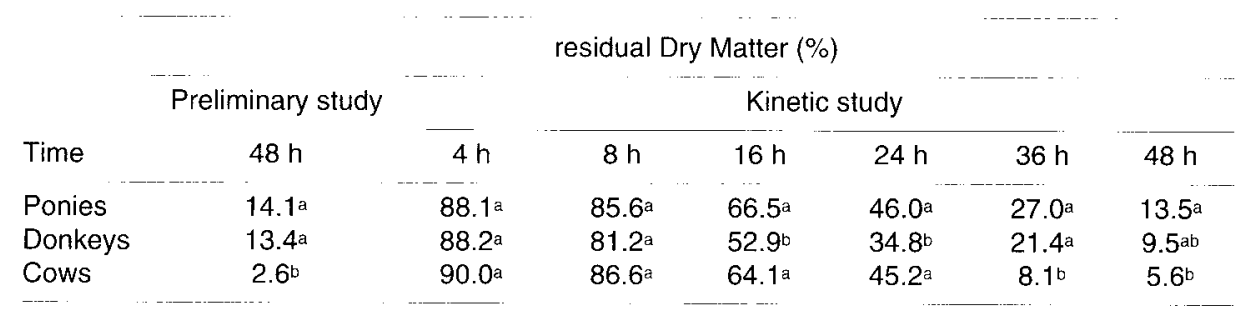

Within the same column a differs statistically from $b$ with $P<0.05$ 